\title{
Multifunctional, biocompatible, non- peptidic hydrogels: from water purification to drug delivery
}

Article

Accepted Version

Baker, B. C., Higgins, C. L., Ravishankar, D., Colquhoun, H. M., Stevens, G. C., Greco, F., Greenland, B. W. and Hayes, W. (2016) Multifunctional, biocompatible, non-peptidic hydrogels: from water purification to drug delivery. Chemistry Select, 1 (8). pp. 1641-1649. ISSN 2365-6549 doi: https://doi.org/10.1002/slct.201600249 Available at https://centaur.reading.ac.uk/66147/

It is advisable to refer to the publisher's version if you intend to cite from the work. See Guidance on citing.

To link to this article DOI: http://dx.doi.org/10.1002/slct.201600249

Publisher: Wiley

All outputs in CentAUR are protected by Intellectual Property Rights law, including copyright law. Copyright and IPR is retained by the creators or other copyright holders. Terms and conditions for use of this material are defined in the End User Agreement. 


\section{CentAUR}

Central Archive at the University of Reading

Reading's research outputs online 


\title{
Multifunctional, Biocompatible, Non-peptidic Hydrogels: from Water Purification to Drug Delivery
}

\author{
Benjamin C. Baker [a]; Clare L. Higgins ${ }^{[a]}$; Divyashree Ravishankar [b]; Howard M. Colquhoun [a]; Gary C. \\ Stevens ${ }^{[c]}$; Francesca Greco ${ }^{[b]}$; Barnaby W. Greenland ${ }^{[b]}$ and Wayne Hayes ${ }^{[a] *}$
}

\begin{abstract}
A novel series of low molecular weight non-peptidic, biocompatible super-hydrogelators with both water purification and drug delivery properties have been developed. Linking the bis aromatic urea groups responsible for gelation together to form biand tri-armed gelators, affords good control over gelation and water purification properties. The use of the gels as effective drug scavengers and delivery systems has been demonstrated with dye substrates, via $\mathrm{pH}$ inversion, as monitored by UV-vis spectroscopy. Finally, the systems' abilities as both drug scavenging and delivery systems have been demonstrated with the clinically-approved drugs chlorpromazine and doxorubicin, respectively.
\end{abstract}

\section{Introduction}

Low molecular weight hydrogelators have gained increasing interest in recent years as a result of the diverse applicability of these systems in areas such as tissue engineering, catalysis and electronics..$^{[1,2]}$ Notably, the use of hydrogelators as water purification systems has been the focus of several research programs. ${ }^{[3-11]}$ The ability to remove large amounts of toxic materials (with respect to toxin:gelator ratio) from aqueous systems, makes such systems advantageous in an industrial setting. ${ }^{[3-11]}$

Many reported low molecular weight hydrogelators can entrap and gel water at levels of less than $1 \%$ by weight of gelator. Termed 'super-gelators', ${ }^{[12]}$ such gels are desirable in drug delivery systems as they possess the stable rheological properties of other gels, but without the need to introduce large quantities of organic matter into the final assembly. Stable, low molecular weight hydrogelators are finding increasing uses as drug delivery systems as a result of their injectibility, ${ }^{[13,14]}$ biocompatibility ${ }^{[15,16]}$ and the ability to control drug release by

[a] B. C. Baker, C. L. Higgins, Prof. H. M. Colquhoun, Prof. W. Hayes Department of Chemistry

University of Reading

Whiteknights, Reading, RG6 6AD, UK.

E-mail:w.c.hayes@reading.ac.uk

[b] D. Ravishankar, Dr. F. Greco, Dr. B. W. Greenland

School of Pharmacy

University of Reading

Whiteknights, Reading, RG6 6AP, UK.

[c] Prof. G. C. Stevens

Gnosys Global Ltd.

17-18 Frederick Sanger Road,

Guildford, Surrey, GU2 7YD, UK

Supporting information for this article is given via a link at the end of the document. varying the gel's rheological properties via the concentration of gelator). ${ }^{[17-19]}$

Here we focus on the development of a non-peptidic hydrogelating system based on the previously reported gelator 1 (Figure 1) that was shown to have suitable characteristics for water purification and drug delivery. ${ }^{[7,8]}$ Whilst there are numerous previous examples of peptide based hydrogelators, [13,20,21] molecules $\mathbf{1}$ and $\mathbf{3}$ (Figure 1) represent non-cytotoxic, non-peptidic hydrogelators capable of both water purification and drug delivery. These non-peptidic gelators have significant advantages over peptidic systems in terms of cost, as well as in the scalability of their synthesis (for example, hydrogelators 1-3 are obtained pure (ca. 1g) without recourse to column chromatography).

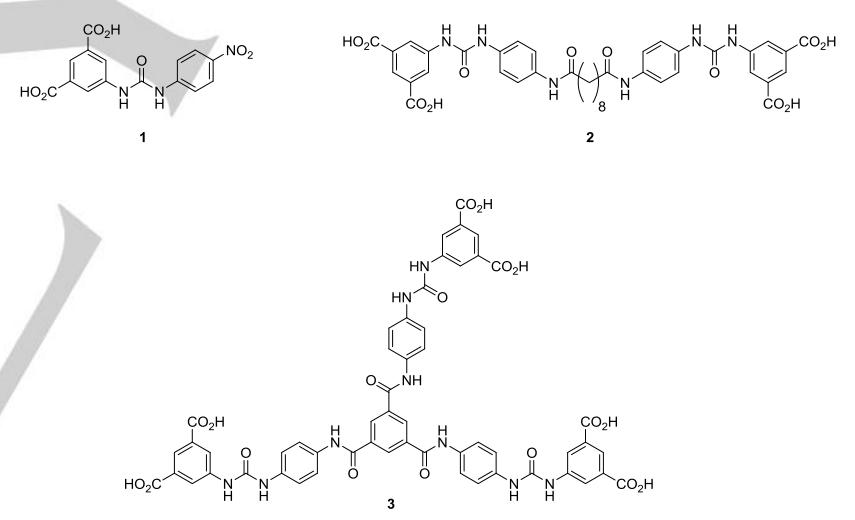

Figure 1. Structures of bis aromatic urea mono and linked hydrogelators 1-3

Low molecular weight heteroaromatic dyes were used to establish the drug scavenging and delivery capabilities of gelators 1-3 (Figure 1). The aromatic moieties present in 1 enhance this gelator's dye-uptake capabilities via $\pi-\pi$ stacking and hydrogen bonding interactions. ${ }^{[7-9]}$ Previous studies have demonstrated that by combining two of the units to form a linked gelator 2 (Figure 1) gelation ability is maintained and dye removal efficiency increased. We now report an extension of this concept to a tri-armed ${ }^{[22]}$ gelator 3 (Figure 1) with greatly improved dye removal capabilities. We also demonstrate the abilities of hydrogelators 1-3 to both selectively and preferentially remove dyes from solutions containing mixtures of dyes. The release of gel-entrapped dyes is achieved via adjustments of the $\mathrm{pH}$ of the gel medium. Finally we demonstrate the potential use of gels 1-3 in the delivery and 
scavenging of aromatic drug molecules having structures complementary to those of the gelating moieties. ${ }^{[23]}$

\section{Results and Discussion}

Synthesis and Characterization of Gelators; The aromatic ureas 1 and $\mathbf{2}$ were synthesized according to previously reported procedures. ${ }^{[7,9]}$ The tri-urea $\mathbf{3}$ was synthesized using an analogous pathway to that used to generate 2 (see Scheme S1) and has been characterized by a combination of spectroscopic techniques. The absence of a primary amine resonance in ${ }^{1} \mathrm{H}$ NMR spectra of tri-urea 3 indicated successful amide formation (see Figure S1-S2). In parallel to this, observation of the downfield shifts of the aromatic resonances when compared to those of the amine starting material (Scheme S1) showed successful formation of the tri-urea $\mathbf{3}$, as reported in previous studies of related molecules. ${ }^{[9]}$ Further proof of the successful synthesis of the tri-urea $\mathbf{3}$ was provided by IR spectroscopy, with the characteristic acyl chloride stretch frequencies $\left(1756 \mathrm{~cm}^{-1}\right)$ and amine overtones (3357 $\mathrm{cm}^{-1}$, Figure S3) of the starting materials not in evidence in the spectrum of the isolated product. The broadened and weakened absorptions associated the carboxyl stretches $\left(1658,1551 \mathrm{~cm}^{-1}\right.$, Figure S4) in comparison to the amidic precursor $\left(1728,1699 \mathrm{~cm}^{-1}\right.$, Figure S3) were attributed to the formation of a hydrogen bonded supramolecular structure. ${ }^{[24]}$ Finally formation of the tri-urea gelator $\mathbf{3}$ was confirmed by ${ }^{13} \mathrm{C}$ NMR spectroscopy and mass spectrometric analyses. The presence of three key ${ }^{13} \mathrm{C}$ carbonyl resonances (at 167.4, 164.5 and 153.2 ppm, Figure S5) and a parent ion in the mass spectrum at $\mathrm{m} / \mathrm{z}=1100.2324$ confirmed formation of the tri-armed gelator 3 (Figure S6).

Gelation studies; Hydrogels of 1-3 were formed using the welldocumented glucono- $\delta$-lactone protocol, which gave stable, transparent gels. Successful gelation of water using compounds 1-3 was confirmed via vial inversion tests (the gels being stable for $>1$ month) and rheological analyses (Table 1, Figure S7), which showed that the gels have a storage modulus an order of magnitude higher than that of the loss modulus. ${ }^{7-9]}$

Table 1. Comparison of the properties of gelators 1-3, Maximum storage (G') and loss moduli (G") (kPa) for hydrogelators 1-3 each at $20 \mathrm{mM} .{ }^{[7,9]}$

\begin{tabular}{cccccc}
\hline Gelator & $\begin{array}{c}\mathrm{CGC} \\
{[\mathrm{mM}]}\end{array}$ & wt \% gel & $\mathrm{G}^{\prime}(\mathrm{kPa})$ & $\mathrm{G}^{\prime \prime}(\mathrm{kPa})$ & $\begin{array}{l}\mathrm{\rho H}(\mathrm{x} \\
\left.10^{22} / \mathrm{g}\right)^{[\mathrm{aa}]}\end{array}$ \\
\hline $\mathbf{1}$ & 0.9 & 0.03 & 294 & 31.5 & 1.57 \\
$\mathbf{2}$ & 1.8 & 0.14 & 327 & 44.5 & 1.36 \\
$\mathbf{3}$ & 1.8 & 0.2 & 250 & 43.2 & 1.47 \\
\hline
\end{tabular}

[a] Density of hydrogen bonding units $\left(\times 10^{22} / \mathrm{g}\right)$
Compounds 1-3 all exhibited super-gelator characteristics $(<1$ wt $\%$ gelator in gel, Table 1). Of particular note are variations in the structural stability of the gels. The increase in storage modulus ( $\left.G^{\prime}\right)$ of the linked bis-armed gelator 2 when compared to that of $\mathbf{1}$ and $\mathbf{3}$ suggests differences in the nature of the supramolecular assembly that results in gelation. This is in agreement with the surfactant-like nature of gelator 2, resulting from the hydrophobic nature of the alkyl linker and the polar urea end group (see hydrogen bonding units/g values Table 1). Moreover, compound $\mathbf{2}$ shows the ability to thermo-gelate in water (a property not demonstrated by gelators 1 and 3 ). [9] Further indications of a different type assembly in gels of $\mathbf{2}$, when compared to those of $\mathbf{1}$ and $\mathbf{3}$, were evident from the dye absorption properties of the linked gelators and also from toxicity studies (see below).

Cytotoxicity testing; To assess the possibility of using hydrogelators 1-3 as drug scavengers and delivery vehicles in vivo, cytotoxicity testing was undertaken. Using the MTT assay ${ }^{[26]}$ it was found that gelators 1 and $\mathbf{3}$ were non-toxic at all the concentrations tested $(0.1-10 \mu \mathrm{M})$ whilst 2 was toxic at concentrations greater than $1 \mu \mathrm{M}$ (Figure 2). These data are in agreement with the surfactant-like nature of gelator $\mathbf{2}$, and are in accordance with variations seen in assembly methods and dye absorption capabilities described previously. ${ }^{[9]}$ To further assess the applicability of the gels as drug delivery/scavenging systems three individual solutions of gels of 1-3 1 and $31 \mathrm{~mL}, 20 \mathrm{mM}, 2$ $1 \mathrm{~mL}, 10 \mathrm{mM})$ were placed in $\mathrm{D}_{2} \mathrm{O}(10 \mathrm{~mL})$ for 1 month at $37^{\circ} \mathrm{C}$ (Figure S8). Dissolved gelator was not detectable via ${ }^{1} \mathrm{H}$ NMR spectroscopic analysis during this period, so it seems that gelators in aqueous environments will not present high enough concentrations to cause a toxic response with respect to cell viability (Figure 2). [27]

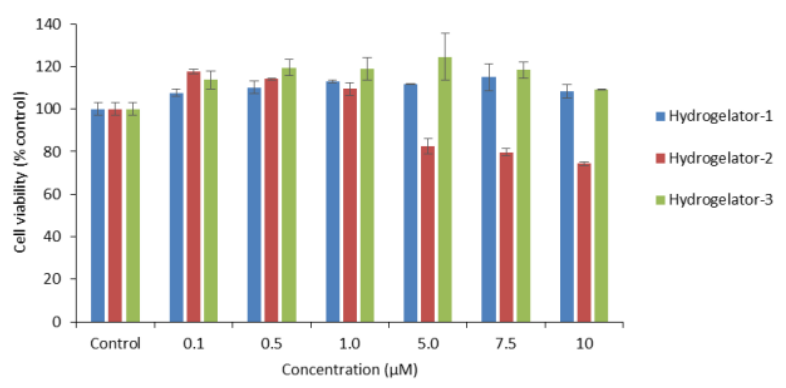

Figure 2. Toxicity of gelators 1-3, evaluated using SH-SY5Y (human neuroblastoma cell line) to test toxicity, with results monitored via MTT assay. ${ }^{[26]}$

Dye extraction studies; To analyze the potential of gelators 1-3 as drug removal and delivery systems aqueous based dyes (Figure S9) were employed as model compounds to investigate the suitability of each system. Visual analysis of the dye-removal capabilities of gels of 1-3 have shown that 3 is by far the most efficient for a range of different dyes when compared to gels formed by $\mathbf{1}$ and $\mathbf{2}$. In each experiment gels (formed at $\mathrm{pH} 4,20$ 
$\mathrm{mM}, 1 \mathrm{~mL}$ for 1 and $3,10 \mathrm{mM}, 1 \mathrm{~mL}$ for 2) formed via glucono- $\delta$ lactone protocol, were added directly via a spatula to an aqueous solution of each respective dye sample $(\mathrm{pH} 7,250 \mathrm{~mL}$, $\left.8 \mathrm{mg} \mathrm{L}^{-1}\right)$ and samples were then removed $(0.5 \mathrm{~mL})$ and filtered $\left(0.45 \mu \mathrm{m}\right.$ Minisart ${ }^{\circledR}$ syringe filter) for $U V / v i s$ spectroscopic analysis as in previous studies. ${ }^{[7-9]}$ Dye removal was monitored from the decrease in the absorption maximum of each dye and then correlated directly to concentration via a calibration curve.

Single dye removal; Previous studies have demonstrated the hydrogelator 1 to be an effective scavenger of Methylene Blue, Methylene Green and Rhodamine B (Figure 3 a)..$^{[7,8]}$ The linkage of two of the moieties responsible for dye absorption, to afford gelator 2, has been shown to increase dye uptake efficiency, ${ }^{\left[{ }^{[]}\right.}$and interestingly the linked gelator $\mathbf{2}$ was here found to absorb dye when used at concentrations of only $10 \mathrm{mM}$, half the value for gels of $\mathbf{3}$ and previously reported for gels of $\mathbf{1}$ (Figure $3 \mathrm{~b}$ ). ${ }^{[9]}$ This observation, combined with the surfactant like nature of gelator 2 (Figure 1 and 2), highlights possible differences in the supramolecular assembly of gels of $\mathbf{2}$ when compared to that of $\mathbf{1}$ and $3 .^{[7-9]}$

The dye removal capability of gelator 3 was assessed via UV/vis spectroscopic analysis with a range of dye types (Figures 3-4). In contrast to gelators $\mathbf{1}$ and 2, $\mathbf{3}$ was found to be extremely efficient for removal of a range of heteroaromatic dyes and, in particular, Methylene Blue, Methylene Green and Direct Red showed complete absorption after 5 minutes (each dye solution of $250 \mathrm{~mL}, 8 \mathrm{mg} \mathrm{L}^{-1}$, gelator 3 added at $1 \mathrm{~mL}, 20 \mathrm{mM}$ ) (Figure 3 c, Figure 4 and Figure S10). The uptake of Methylene Blue by 3 was determined to be $1450 \mathrm{mg} \mathrm{g}^{-1}$ (dye:gel), a value greater than that reported for $\mathbf{1}$ and $\mathbf{2} \cdot{ }^{[7-9]}$
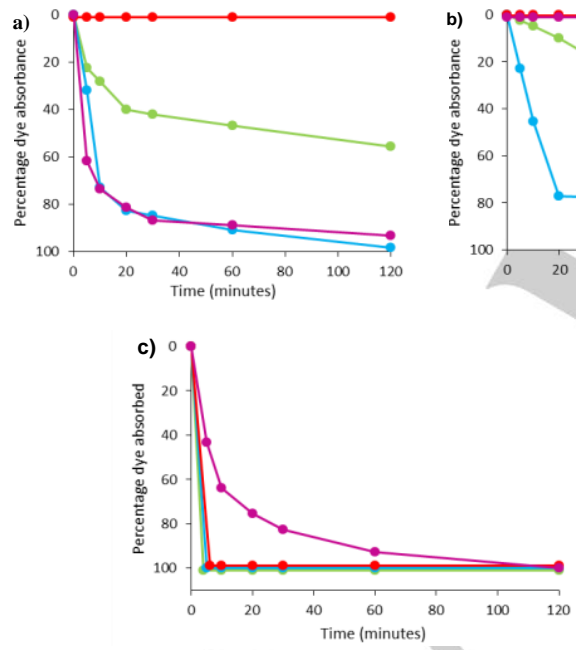

Figure 3. UV/vis absorption spectra of stirred solutions of aqueous Methylene Blue, Direct Red, Methylene Green and Rhodamine B (250 mL, $\left.8 \mathrm{mg} \mathrm{L}^{-1}\right)$ after addition of $1 \mathrm{~mL}$ of hydrogelator; a) $1(1 \mathrm{~mL}, 20 \mathrm{mM})$, b) $2(1 \mathrm{~mL}, 10 \mathrm{mM})$ and c) $3(1 \mathrm{~mL}, 20 \mathrm{mM})$, and stirring for allotted timeframe. Complete removal of Methylene Green and Rhodamine B via gels of 1 were observed only after 3 days.
Furthermore the removal of Direct Red, achieved via gelator 3 (Figure $3 \mathrm{c}$, Figure 4), was not observed for either gelator 1 or 2 (a, b Figure 3, Table S1). It is proposed that uptake of Direct Red occurs as a result of the increased functionality of gelator 3 enabling increased interactions with the higher molecular weight dye (with respect to Methylene Green and Methylene Blue, Figure S9), via combinations of hydrogen bonding and $\pi-\pi$ stacking (vide infra). ${ }^{[7,8,17]}$

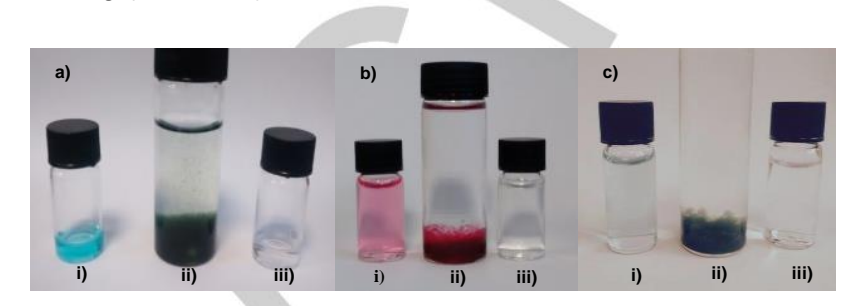

Figure 4. Removal of single dyes: a) Methylene Blue b) Direct Red c) Methylene Green (250 mL, $8 \mathrm{mg} \mathrm{L}^{-1}$ ): (i) before gelator addition, (ii) after addition of hydrogelator $3(1 \mathrm{~mL}, 20 \mathrm{mM})$ and stirring (5 minutes) and (iii) after filtration of gelator.

It is noted that the removal of the dye Rhodamine B did not occur with comparable efficiencies to Methylene Blue/Green or Direct Red (c, Figure 3) employing gelator 3. Interestingly analogous results were not observed using gelator 1 (a Figure 3 and Figure S11-S12). It is suggested that the carboxylic acid moiety of the Rhodamine $\mathrm{B}$ dye competitively binds to the carboxylic functionalized gelator $\mathbf{3}$ to hinder effective fibril formation and so diminish dye uptake (Figure S9). ${ }^{[7,8,9]}$ Such results were not seen with the mono-armed gelator $\mathbf{1}$, which relies on hydrogen bonding nitro-urea interactions to effectively form a stable gel. ${ }^{[7]}$

To understand the binding motifs underpinning the dye uptake by gelator 3 , dilution studies using ${ }^{1} \mathrm{H}$ NMR spectroscopy were undertaken on samples of the gelator and dyes Rhodamine $B$ and Methylene Blue ( $a$ and $b$, respectively, see Figure 5). Spectra were acquired in the dipolar aprotic solvent DMSO- $d_{6}$ to avoid gelation during the NMR study. Of note, and apparent in both studies, is the splitting of the resonances associated with the central core aromatic moieties in gelator 3 with increasing dye concentration (see $\mathrm{H}_{8}$, Figure 5). It is proposed that such splitting arises from the presence of unbound and bound gelator (with respect to the dye), implying slow exchange on the NMR timescale. ${ }^{[28,29]}$ The multiplicity and chemical shift of resonances associated with the urea protons of the gelator $\left(\mathrm{H}_{3-4}\right.$ Figure 5) also indicate a breakdown in the intermolecular hydrogen bonding interactions between the gelator molecules and an increase in those between gelator and dye, suggesting that this is a key interaction for dye absorption, facilitating dye removal in aqueous solvents yet resulting in shortening in fibril structure and gel weakening as is noted in previous studies (vide infra)..$^{7-}$ $9,27,30]$ Finally, shifts in the resonances associated with linking and terminal aromatic rings 


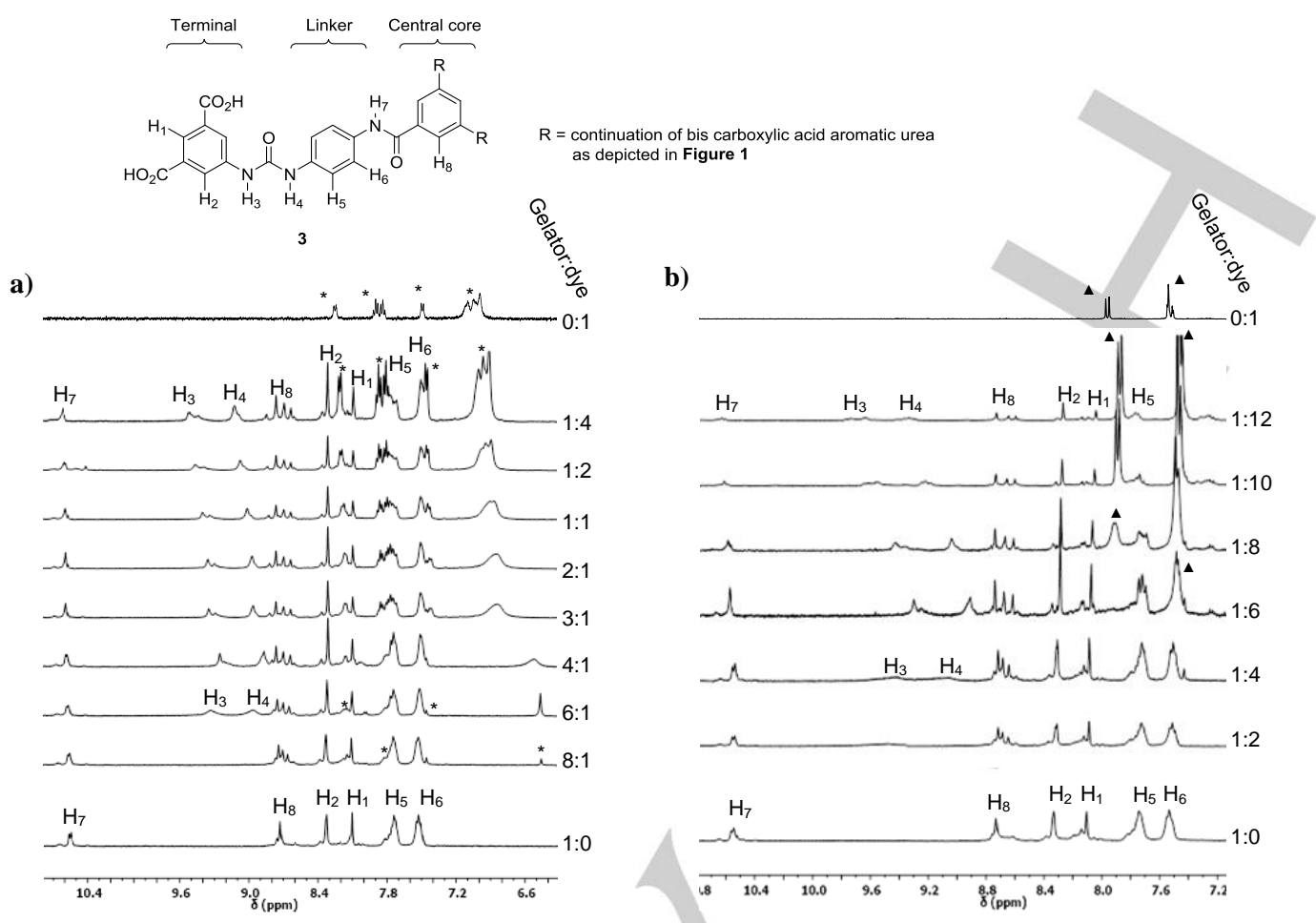

Figure 5. a) ${ }^{1} \mathrm{H}$ NMR spectra of hydrogelator 3 and Rhodamine $B\left({ }^{*}\right.$ denoting resonances associated with the dye, in non-gelling solvent DMSO- $\left.d_{6}\right)$ where the bottom spectrum is pure 3, and top is pure Rhodamine B (mixtures 8:1, 6:1, 4:1, 3:1, 2:1, 1:1, 1:2, 1:4, in ascending order, mol:mol, 3:Rhodamine B); b) ${ }^{1} \mathrm{H}$ NMR spectra of hydrogelator 3 and Methylene Blue ( ${ }^{\wedge}$ denoting resonances associated with the dye, in non-gelling solvent DMSO- $d_{6}$ ) where the bottom spectrum is pure 3, top is pure Methylene Blue (mixtures 1:2, 1:4, 1:6, 1:8, 1:10, 1:12, in ascending order, mol:mol, 3:Methylene Blue).

$\left(\mathrm{H}_{1-2,5-6}\right.$ in Figure 5$)$ in both dilution studies suggests $\pi-\pi$ stacking is an additional driving force behind dye absorption in the gel, as reported in equivalent studies on gelators 1 and $2 .^{[7-9]}$

Differences to note include the level of dye loading (with respect to gelator) necessary to produce the same shifts of the gelator urea, amide and central core resonances when comparing the two dyes. In studies of binding between gelator and Rhodamine $\mathrm{B}$, splitting of the central core aromatic resonance $\left(\mathrm{H}_{8}\right.$ Figure 5$)$ was observed at a molar ratio of 6:1 (gelator:dye), with gelator urea resonances $\left(\mathrm{H}_{3-4}\right.$ Figure 5$)$ appearing at a ratio of $4: 1$. In analogous binding studies of the gelator with Methylene Blue, splitting of the central core aromatic resonance was not observed until a molar ratio of 1:4 (gelator:dye) was reached, and urea resonances did not appear until a molar ratio of $1: 6$ was achieved. Such a large increase in the level of dye needed to implement such changes in the spectra reflects the increased efficiency of the gelator to bind to Methylene Blue dye when compared with Rhodamine B (directly related to dye removal studies in aqueous environments). Indeed, the efficiency of dyegelator binding is such that at a molar ratio of $1: 8$ ratio (gelator:dye) free Rhodamine $\mathrm{B}$ dye was not detectable by ${ }^{1} \mathrm{H}$ NMR spectroscopic analysis (Figure $5 b$ )

In attempts to understand the differences in efficiency of the dye uptake of Rhodamine B and Methylene Blue by gelator 3, shifts in comparable proton resonances were analyzed. No significant differences were observed in the amide and urea shifts $\left(\mathrm{H}_{7}\right.$ and
$\mathrm{H}_{3-4}$, respectively, Figure 5), but analysis of the terminal aromatic resonances $\left(\mathrm{H}_{1-2}\right.$ Figure 5$)$ demonstrated a much larger shift with Methylene Blue than with Rhodamine B. Attempts to analyze linker aromatic shifts $\left(\mathrm{H}_{5-6}\right.$ Figure 5$)$ were complicated by gel/dye resonance overlap. It is suggested that increased $\pi-\pi$ stacking interactions between the gelator and Methylene Blue when compared to Rhodamine $B$ is the driving force behind increased efficiency of uptake of the former dye. ${ }^{[7-9]}$

Small angle X-ray scattering (SAXS) analysis of gels of 3 both before and after Methylene Blue absorption were undertaken to further ascertain method of dye removal. Prior to dye absorption, no significant scattering was observed (Figure S13), consistent with the amorphous nature of the gel. However, after dye absorption, small-angle scattering was observed corresponding to a d-spacing of approximately $300 \AA$ (Figure S14). It has been suggested in the literature that such scattering occurs as a result of the intercalation of the dye into the fibrils of the gelator, disrupting the fibrils assembly and thus length due to the increased propensity for disassociation from the gel bulk resulting in detection (as noted in other dye absorption studies on gels of 1$) \cdot{ }^{[7,8]}$

Finally it is noted that absorption studies of gelators 1-3 with the azide functionalized dye Direct Orange each showed no significant dye removal, highlighting the need for the structure of the dye to resemble that of the gelator for successful removal. 
This proved important in the sequential dye-removal studies reported below. ${ }^{[7]}$

Sequential dye removal; It was decided to compare the most versatile dye removal gelators $\mathbf{1}$ and $\mathbf{3}$ (Figure 3 ) in selective dye removal studies. Primarily the effect of the comparison of selective removal of Methylene Blue from mixtures of Direct Orange and Methylene Blue $\left(250 \mathrm{~mL} \mathrm{H}_{2} \mathrm{O}, 4 \mathrm{mg} \mathrm{L}^{-1}, 1: 1\right.$ wt $\%$ dye) was studied in both gelators $(1 \mathrm{~mL}, 20 \mathrm{mM})$. It was found that both gelators were able to successfully remove the Methylene Blue from the solution of mixed dyes (Figure 6 and Figure S15). The presence of the non-absorbed Direct Orange did not have an effect on the uptake efficiency of gelators 1 or 3 (Figure 6 b) for Methylene Blue.
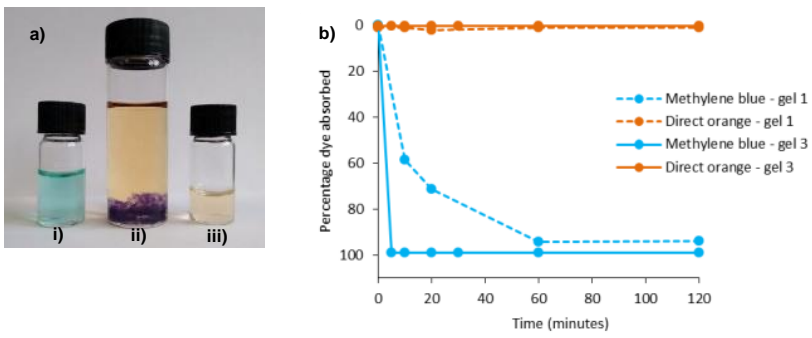

Figure 6. Selective removal of Methylene Blue from Methylene Blue:Direct Orange aqueous solution ( $250 \mathrm{~mL}, 4 \mathrm{mg} \mathrm{L}^{-1}, 1: 1 \%$ wt dye) after addition of 1 $\mathrm{mL}$ of hydrogelator 1 or $3(1 \mathrm{~mL}, 20 \mathrm{mM})$ where; a) i) Methylene Blue:Direct Orange solution, ii) after addition of gel of $\mathbf{3}$ and five minutes stirring, iii) after filtration of gel, b) percentage absorption of dyes after addition of hydrogelators 1 and $\mathbf{3}(1 \mathrm{~mL}, 20 \mathrm{mM})$.

In a further selectivity experiment, the absorption capabilities of gelators 1 and $3(1 \mathrm{~mL}, 20 \mathrm{mM})$ in mixtures of Direct Red/Methylene Blue aqueous solutions (250 mL, $4 \mathrm{mg} \mathrm{L}^{-1}, 1: 1 \%$ wt dye) were compared. Gelator 3 successfully removed both dyes from solution, although the rate of removal was effectively halved, now taking 10 minutes for complete dye removal (Figure 7 and Figure S16). It was observed that in the removal of Methylene Blue, Gelator 1 was hindered in presence of the Direct Red (Figure 7 and Figure S16), indeed subsequent release of the dyes after 30 minutes stirring was observed. This observation supports the hypothesis that the density of functional groups capable of supramolecular interactions within the gelator has a direct effect on its dye removal capabilities.

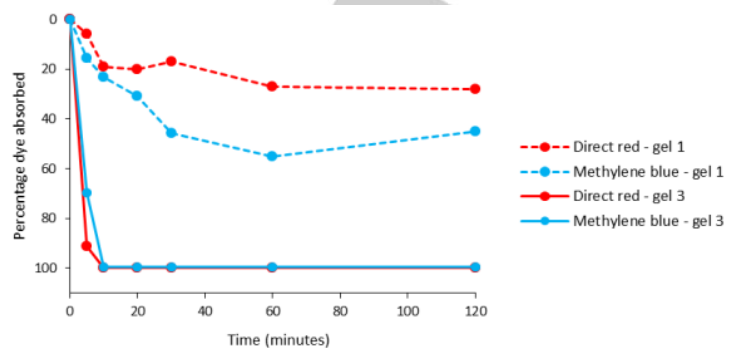

Figure 7. Absorption of Methylene Blue and Direct Red from a mixed aqueous solution (250 mL, $4 \mathrm{mg} \mathrm{L}^{-1}, 1: 1$ wt\% dye) after addition of $1 \mathrm{~mL}$ of hydrogelators 1 or $3(1 \mathrm{~mL}, 20 \mathrm{mM})$.
The rate of dye removal by gelator 3 was further demonstrated by preferential dye removal experiments. Rhodamine $B$ and Methylene Blue were selected in combination as a result of the variation in absorption rates (Figure $3 \mathrm{c}$ ). The dyes were mixed in a wt/wt ratio of $1: 1\left(250 \mathrm{~mL}, 4 \mathrm{mg} \mathrm{L}^{-1}\right)$ and gelator 3 was added $(1 \mathrm{~mL}, 20 \mathrm{mM})$ as in previous examples. Preferential absorption of Methylene Blue was shown (99\% absorbed, Figure $8 \mathrm{c}$ ) in comparison to Rhodamine B (5\% absorbed, Figure 8c) (Figure S17). The presence of Rhodamine B had no impact on the rate of Methylene Blue absorption, with this dye being removed completely after 5 minutes. Interestingly it was found that the remaining Rhodamine $B$ was absorbed after addition of a larger volume of gelator 3 to the mixture $(3 \mathrm{~mL}, 20 \mathrm{mM})$ (Figure 8 and Figure S17), but at a decreased rate with respect to gelator:dye volume (see Figure 3 for a comparison).

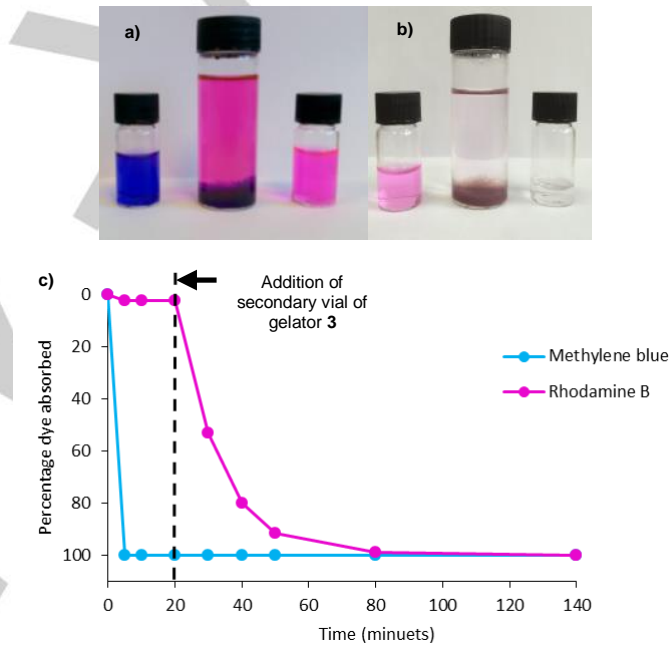

Figure 8. a) Preferential removal of Methylene Blue from Methylene Blue:Rhodamine B aqueous solution ( $250 \mathrm{~mL}, 4 \mathrm{mg} \mathrm{L}^{-1}, 1: 1 \%$ wt dye) (see i) after addition of $1 \mathrm{~mL}$ of hydrogelator $3(1 \mathrm{~mL}, 20 \mathrm{mM}$ ) (see ii) and filtration (see iii) b) removal of Rhodamine $B$ from same mixture as b (see i) after second addition of hydrogelator $3(3 \mathrm{~mL}, 20 \mathrm{mM}$ ) (see ii) and filtration (see iii) c) percentage absorption showing same selective dye removals as a and b.

In order to explore the possibilities of $\mathrm{pH}$-induced molecular release, a process relevant to drug delivery and gel regeneration, ${ }^{[2,18,31]}$ the release of absorbed Methylene Blue via $\mathrm{pH}$ variation was studied with gelators 1-3. The gelator and aqueous dye solutions were prepared as in previous experiments, and the dye was absorbed onto the gelator from solution. The $\mathrm{pH}$ of the solution was varied by addition of either $\mathrm{NaOH}_{(\mathrm{s})}$ or $\mathrm{HCl}_{\text {(conc) }}$ to minimise volume and concentration variation. The $\mathrm{pH}$ was varied between 7 and 9 to effect dye adsorption and release.

It was observed that upon raising the $\mathrm{pH}$ to 9 , breakdown of the gel structure (leading to dissolution and dilution of the gelators in the bulk solvent) allowed release of absorbed Methylene Blue (Figure 9). Using the ratios derived from dilution studies (see Figure S18) the percentage release of dye at a given $\mathrm{pH}$ could 
be calculated for each gelator. It was apparent that gelator 2 releases the dye at the fastest rate, with $100 \%$ release being achieved in less than 2 hours (Figure 9, Figure S19). However, it is noted that the gels of this system are formed at half the concentration of $\mathbf{1}$ and $\mathbf{3}$ as a result of the different assembly and absorption properties of 2 . Gels of $\mathbf{1}$ and $\mathbf{3}$ showed slower release of Methylene Blue, with $\mathbf{3}$ achieving a higher final level $(90 \%)$ of release than $1(60 \%)$.

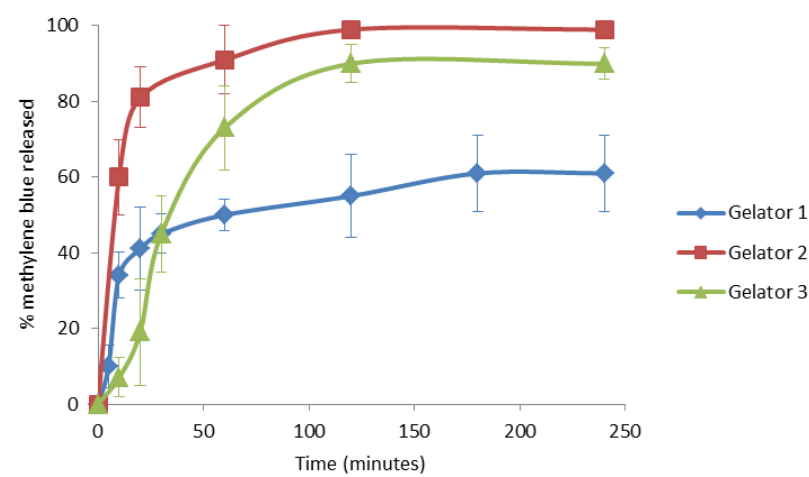

Figure 9. Percentage release of Methylene Blue dye from gels of 1-3 (for 1

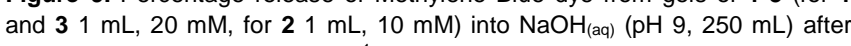
Methylene Blue (250 mL, $\left.4 \mathrm{mg} \mathrm{L}^{-1}\right)$ has been absorbed onto gelators.
Blue (Figure S21), and its toxic effects at high dosage. ${ }^{[32]}$ It was found that gels of $\mathbf{3}$ were able to remove the drug efficiently from $\mathrm{D}_{2} \mathrm{O}$ in 10 minutes, as monitored via ${ }^{1} \mathrm{H}$ NMR spectroscopy (Figure 10), using the same removal protocols as those described previously.

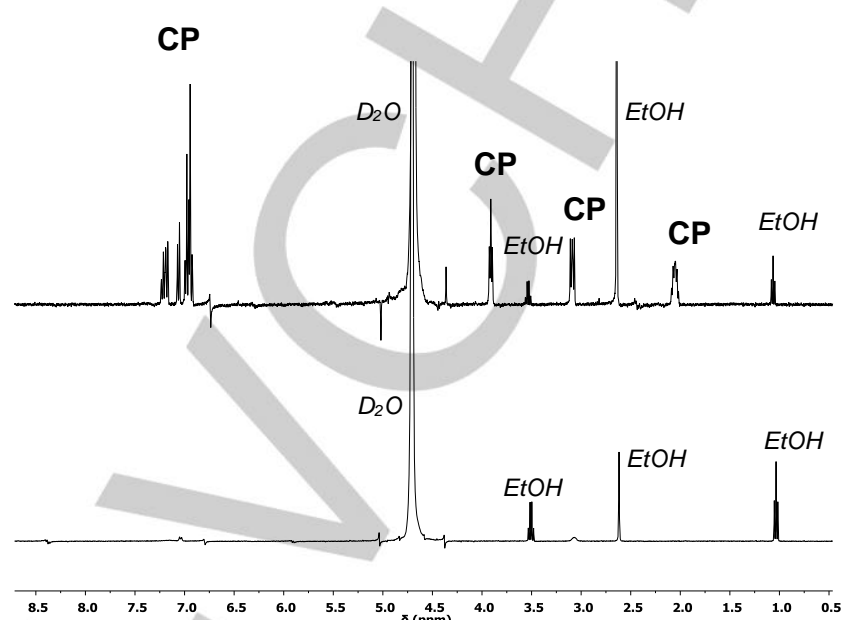

Figure 10. ${ }^{1} \mathrm{H}$ NMR spectra showing removal of chlorpromazine (CP) from $\mathrm{D}_{2} \mathrm{O}$. Top: chlorpromazine $8 \mathrm{mg} / \mathrm{ml}(25 \mathrm{~mL})$ spiked with ethanol as a reference $(10 \mu \mathrm{m})$. Bottom: sample after stirring with gel of $3(1 \mathrm{~mL}, 20 \mathrm{mM})$ for 10 minutes.
The versatility of gelator $\mathbf{3}$, in terms of dye removal/release was also demonstrated via multiple absorption/release cycles (Table 2 and Figure S20). As is shown the cycles have minimal impact on the ability of the gelator to absorb/release dyes effectively.

Table 2. Percentage absorption and release of Methylene Blue dye via $\mathrm{pH}$ switching of a solution containing Methylene Blue $\left(250 \mathrm{~mL}, 8 \mathrm{mg} \mathrm{L}^{-1}\right)$ and gelator $3(1 \mathrm{~mL}, 20 \mathrm{mM})$.

\begin{tabular}{ccc}
\hline Gelator & $\begin{array}{c}\mathrm{CGC} \\
{[\mathrm{mM}]}\end{array}$ & wt \% gel \\
\hline $\mathbf{1}$ & 0.9 & 0.03 \\
$\mathbf{2}$ & 1.8 & 0.14 \\
$\mathbf{3}$ & 1.8 & 0.2 \\
\hline $\begin{array}{l}\text { [a] Density of hydrogen bonding units } \\
\text { (× 1022/g) }\end{array}$
\end{tabular}

Drug scavenging and delivery; To assess the possibility of the use of the gelators as drug removal motifs from aqueous solution 3 was selected as the model system, being the most efficient gelator for dye-removal (see Figures 3, 6 and 7) and non-cytotoxic (Figure 2). Chlorpromazine was chosen as a model drug, as a result of its structural similarity to Methylene
Based upon the mechanical stability (Table 1), non-cytotoxicity (Figure 2) and release duration (Figure 9) hydrogelator 1 was selected as a model system to investigate drug release via diffusion over the other two gelators. The system also demonstrates gel re-formation properties after disruption and injection suitable for drug delivery (recovery of storage modulus ${ }^{[7]}$ achievable 5 minutes after injection and vial inversion stability after 20 minutes Figure S22-3), not released in either of the other two gelators. Doxorubicin was selected as the drug for delivery after it was ascertained that drug release would not be hindered via intercalation into the gel fibrils and hence reabsorption (monitored via UV/vis spectra readings under same method as dye uptake, gel of $1,1 \mathrm{~mL} 20 \mathrm{mM}$ being placed into a stirred solution of doxorubicin $10 \mathrm{~mL} 0.1 \mathrm{mg} / \mathrm{mL}$ ) (attributed to the dissimilarity between the drug and previously mentioned dyes, Figures S9 and S21).

Two gel samples were prepared via dissolution of gelator 1 (20 $\mathrm{mM}$ and $80 \mathrm{mM})$ in $\mathrm{NaOH}_{(\mathrm{aq})}(0.01 \mathrm{M}, 0.5 \mathrm{~mL})$. Doxorubicin $(0.2$ $\mathrm{mL}, 0.1 \mathrm{mg} / \mathrm{mL}$ ) was introduced via dilution in $\mathrm{HCl}_{(\mathrm{aq})}(0.02 \mathrm{M}$, $0.3 \mathrm{~mL}$ ) and addition to gelator $1 \mathrm{NaOH}_{(\mathrm{aq})}$ solution to achieve gelation. The gels were then injected into phosphate buffer saline solution and held at $37^{\circ} \mathrm{C}$ over a period of 1 month. Drug release was monitored via UV/vis spectroscopic analysis, correlating the absorption maxima of doxorubicin $(485 \mathrm{~nm})$ with percentage release, as in the dye-release studies described above.

Gelator 1 proved to be an effective release system, and the rate of release was controllable via gelator concentration (Figure 11 
and Figures S24 - S25). ${ }^{[7,17-19,33]}$ At both gelator concentrations, a burst release was observed within the first 24 hours (the level of release directly related to gelator concentration), after which Fickian-like delivery predominated at both concentrations. ${ }^{[17-19,33]}$ Finally, plateauing was recorded in both concentrations when drug delivery exceeded $90 \%$.

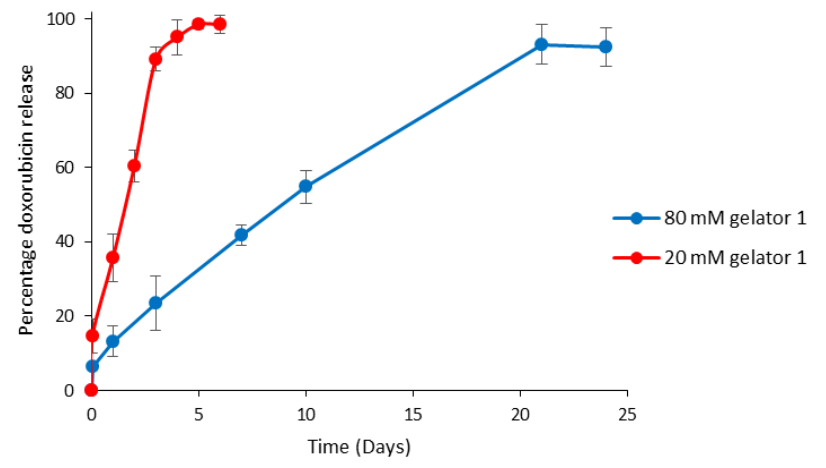

Figure 11. Release of doxorubicin $(0.02 \mathrm{mg})$ from gelator 1 (at concentrations of $20 \mathrm{mM}$ and $80 \mathrm{mM}, 1 \mathrm{~mL}$ ) into phosphate buffer saline solution.

\section{Conclusions}

It has been demonstrated that a range of hydro-super-gelators can be synthesised with a bis aromatic urea motif. These supergelators have demonstrated significant water purification properties via gelator-impurity (dye) binding. Linking the motifs responsible for binding creates a significant improvement on the ability of the resulting gels to purify water. The ability of such gels to preferentially and sequentially remove species from aqueous environments has been demonstrated. It has also been demonstrated that absorbed species contained within the formed gels can be released by $\mathrm{pH}$ switching.

Furthermore it has been demonstrated that the tris armed gelator can effectively remove model drug compounds from aqueous solutions. The mono armed gelator 1 can also successfully release model drugs via diffusion, with release rates controllable via the concentration of the formed gelators. Combined with the biocompatibility of the two hydrogelators 1 and $\mathbf{3}$, and injectability of the mono gelator $\mathbf{1}$ it is suggested that they would be suitable as both drug-release and drugscavenging agents.

\section{Acknowledgements}

The authors would like to acknowledge financial support from the University of Reading and Gnosys Global Ltd (PhD studentship for BCB). In addition, the University of Reading (EPSRC- Doctoral Training Grant) is acknowledged for granting access to instrumentation in the Chemical Analysis Facility. Professor I. W. Hamley is acknowledged for access to rheological facilities and C. Picken, M. Lines and T. Wong for their previous studies.

Keywords: hydrogelator $\cdot$ sequential absorbance $\cdot$ dye release $\bullet$ drug delivery $\cdot$ biocompatibility

[1] a) J. W. Steed, Chem. Soc. Rev., 2010, 39, 3686-3699, b) K. J. Skilling, F. Citossi, T. D. Bradshaw, M. Ashford, B. Kellam, M. Marlow Soft Matter, 2014, 10, 237-256, c) D. Dias Dias, D. Kuhbeck, R. J. Koopmans, Chem. Soc. Rev., 2011, 40, 427-448, d) B. Escuder, F. Rodriguez-Llansola, J. F. Miravet, New. J. Chem., 2010, 34, 1044-1054.

[2] R. G. Weiss, J. Am. Chem. Soc., 2014, 136, 7519-7530.

[3] T. Kar, S. Debnath, D. Das, A. Shome, P. K. Das, Langmuir, 2009, 25, 8639-8648.

[4] V. Bekiari, P. Lianos, Chem. Mater., 2006, 18, 4142-4146.

[5] S. Ray, A. K. Das, A. Banerjee, Chem. Mater., 2007, 19, 1633-1639.

[6] B. D. Okesola, D. K. Smith, Chem. Commun., 2013, 49, 11164-11166.

[7] F. Rodríguez-Llansola, B. Escuder, J. F. Miravet, D. Hermida-Merino, I. W. Hamley, C. J. Cardin, W. Hayes, Chem. Commun., 2010, 46, 7960 7962.

[8] D. M. Wood, B. Greenland, A. L. Acton, F. Rodríguez-Llansola, C. A Murray, C. J. Cardin, J. F. Miravet, B. Escuder, I. W. Hamley, W. Hayes, Chem. Eur. J., 2012, 18, 2692 -2699.

[9] B. C. Baker, A. L. Acton, G. C. Stevens, W. Hayes, Tetrahedron, 2014 70, 8303-8311.

[10] a) B. Adhikari, G Pauli, A. Banerjee, Soft Matter, 2009, 5, 3452-3460, b) J. Wanga, H. Wang, Z. Song, D. Kong, X. Chen, Z. Yang, Coll. Surf. B: Biointerfaces, 2010, 80,155-160, c) Y. Tang, X. Dou, Z. Ji, P. Li, S. Zhu, J. Gu, C. Feng, D. Zhang, J. Mol. Liq., 2013, 177, 167-171, d) H. Wang, W. Xu, S. Song, L. Feng, A. Song, J. Hao, J. Phys. Chem. B, 2014, 118 4693-4701.

[11] Y. Sil Jeon, J. Ind. Eng. Chem., 2008, 14, 726-731,

[12] K. Murata, M. Aoki, T. Suzuki, T. Harada, H. Kawabata, T. Komori, F. Ohseto, K. Ueda, S. Shinka, J. Am. Chem. Soc., 1994, 116, 6664-6676.

[13] D. J. Adams, P.D. Topham, Soft Matter, 2010, 6, 3707-3721.

[14] F. Rodríguez-Llansola, D. Hermida-Merino, B. Nieto-Ortega, F. J. Ramírez, J. T. López Navarrete, J. Casado, I. W. Hamley, B. Escuder W. Hayes, and J. F. Miravet, Chem. Eur. J., 2012, 18, 14725-14731.

[15] N. Javid, S. Roy, M. Zelzer, Z. Yang, J. Sefcik, R. Uljin, Biomacromolecules, 2013, 14, 4368-4376.

[16] J. F. Miravet, B. Escuder, ed. H. J. Schneider, Supramolecular systems in Biomedical fields, The Royal Society of Chemistry, Cambridge, U.K., 2013, pp 331-354

[17] a) E. J. Howe, B. O. Okesola, D. K. Smith, Chem. Commun., 2015, 51, 7451-7454, b) B. O. Okesola, V. M. P. Vieira, D. J. Cornwell, N. K Whitelaw, D. K. Smith, Soft Matter, 2015,11, 4768-4787, c) J. Buendía, E. Matesanz, D. K. Smith, L. Sánchez, Cryst. Eng. Comm., 2015, 17, 8146-8152

[18] a) A. Vintiloiu, J. C. Leroux, J. Control. Release, 2008, 125, 179-192, b) K. J. Skilling, F. Citossi, T. D. Bradshaw, M. Ashford, B. Kellam, M. Marlow, Soft Matter, 2014,10, 237-256.

[19] a) L. E. Buerkle, S. J. Rowan, Chem. Soc. Rev., 2012, 41, 6089-6102, b) A. Z. Cardoso, L. L. E. Mears, B. N. Cattoz, P. C. Griffiths, R. Schweinsc, D. J. Adams, Soft Matter, 2016, 12, 3612-3621.

[20] P. W. J. M. Frederix, G. G. Scott, Y. M. Abul-Haija, D. Kalafatovic, C. G. Pappas, N. Javid, N. T. Hunt, R. V. Ulijn, T. Tuttle, Nature Chemistry, 2015, 7, 30-37.

[21] R. Tian, J. Chen, R. Niu, Nanoscale, 2014, 6, 3474-3482.

[22] a) R. C. T. Howe, A. P. Smalley, A. P. M. Guttenplan, M. W. R Doggett, M. D. Eddleston, J. C. Tan, G. O. Lloyd, Chem. Commun. 2013, 49, 4268-4270, b) S. Cantekin, T. F. A. de Greef, A. R. A. Palmans, Chem. Soc. Rev., 2012, 41, 6125-6137, c) A. Friggeri, C. van der Pol, K. J. C. van Bommel, A. Heeres, M. C. A. Stuart, B. L. Feringa, 
J. van Esch, Chem. Eur. J., 2005, 11, 5353-5361, d) J. P. Mathias, E. E. Simanek, G.M. Whitesides, J. Am. Chem. soc., 1994, 116, 4326-4340, e) A. R. A. Palmans, J. A. J. M. Vekemans, R.t A. Hikmet, H. Fischer, E. W. Meijer, Adv. Mater., 1998, 10, 873-876.

[23] S. Fleming, S. Debnath, P. Frederix, N. Hunt, R. Uljin, Biomarcromolecules, 2014, 15, 1171-1184.

[24] a) K. Hanabusa, M. Yamada, M. Kimura, H. Shirai, Angew. Chem. Int. Ed., 1996, 35, 1949-1951, b) P. Martinetto, P. Terech, A. Grand, R Ramasseul, E. Dooryhée, M. J. Anne, Phys. Chem. B., 2006, 110 15127-15133.

[25] D. J. Adams, M. F. Butler, W. J. Frith, M. Kirkland, L. Mullen, P. Sanderson, Soft Matter, 2009, 5, 1856-1862.

[26] T. Mosmann, J. Immunol. Methods, 1983, 65, 55-63.

[27] B. Escuder, M. Llusar, J. F. Miravet, J. Org. Chem., 2006, 71, 77477752.

[28] J. A. Foster, R. M. Edkins, G. J. Cameron, N. Colgin, K. Fucke, S. Ridgeway, A. G. Crawford, T. B. Marder, A. Beeby, S. L. Cobb, J. W. Steed, Chem. Eur. J. 2014, 20, 279-291.

[29] S. Mukherjee, B. Mukhopadhyay, RSC Advances, 2012, 2, 2270-2273.

[30] M. de Loos, J. van Esch, R.M. Kellog, B.L. Feringa, Angew. Chem. Int. Ed., 2001, 40, 613-616.

[31] K. J. Skilling, F. Citossi, T. D. Bradshaw, M. Ashford, B. Kellam, M. Marlow, Soft Matter, 2014, 10, 237-256.

[32] A. A Monte, R. Chuang, M. Bodmer, Br. J. Clin. Pharmacol., 2010, 70, 794-798.

[33] C. Yan, D. J. Pochan, Chem. Soc. Rev., 2010, 39, 3528-3540. 
Entry for the Table of Contents (Please choose one layout)

Layout 2:

\section{FULL PAPER}
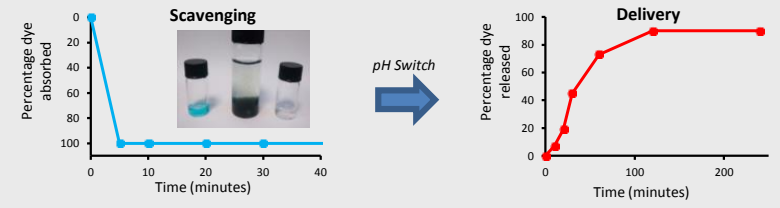

Herein we describe the synthesis and properties of three generations of low molecular weight non-peptidic super hydrogelators. These non-cytotoxic super hydrogelators exhibit both water purification and drug delivery properties via the controlled uptake of aromatic based dyes and release of the clinically-approved drugs chlorpromazine and doxorubicin.
Benjamin C. Baker; Clare L. Higgins, Divyashree Ravishankar; Howard M. Colquhoun; Gary C. Stevens; Francesca Greco; Barnaby W. Greenland and Wayne Hayes

Page $x x$. - Page $x x$.

Multifunctional, Biocompatible, Nonpeptidic Hydrogels: from Water Purification to Drug Delivery 